\title{
Effect of ibuprofen on extracellular polymeric substances (EPS) production and composition, and assessment of microbial structure by quantitative image analysis
}

\author{
António Melo, Joana Costa, Cristina Quintelas, Eugénio C. Ferreira, Daniela P. Mesquita \\ CEB - Centre of Biological Engineering, Universidade Do Minho, Campus de Gualtar, 4710-057, Braga, Portugal
}

\section{A R T I C L E I N F O}

\section{Keywords:}

Activated sludge

Extracellular polymeric substances

Loosely bound EPS

Tightly bound EPS

Quantitative image analysis

\begin{abstract}
A B S T R A C T
A Sequencing Batch Reactor (SBR) with activated sludge was operated with synthetic wastewater containing ibuprofen (IBU) to investigate the biomass stress-responses under long-term IBU exposure. There were 3 different phases: phase I as the control without IBU for 56 days, phase II (40 days), and phase III (60 days) containing IBU at 10 and $5 \mathrm{mg} \mathrm{L}^{-1}$ each. The overall performance of the SBR as well as the extracellular polymeric substances (EPS) in terms of polysaccharides, proteins, and humic acid substances were estimated. Morphological parameters of microbial aggregates in the presence of IBU (phase II and phase III) were assessed by quantitative image analysis (QIA). Removal efficiencies of chemical oxygen demand (COD) and ammonium ( $\mathrm{NH}_{4}^{+}$) were significantly reduced by IBU. Loosely bound EPS (LB-EPS) decreased during phase II and phase III, and tightly bound EPS (TBEPS) was slightly higher in phase II than phase I. TB-EPS proteins were greater in phase II, perhaps to protect microbial cells from IBU exposure. These findings provided insight into both activated sludge stress-responses and EPS composition under long-term IBU exposure. Spearman correlation showed that EPS and morphological parameters significantly affected sludge settleability and flocculation. QIA also proved to be a powerful technique in investigating dysfunctions in activated sludge under IBU exposure.
\end{abstract}

\section{Introduction}

The presence of pharmaceutical compounds in the environment has become a growing concern worldwide. Albeit these compounds are present at low concentrations $\left(<1 \mathrm{mg} \mathrm{L}^{-1}\right)$ in aquatic environments, these substances are capable of triggering extremely harmful effects in the systems in which they can be found (Joss et al., 2006; Sacher et al., 2001; Santos et al., 2010).

Ibuprofen (IBU) is a non-steroidal anti-inflammatory drug used to reduce fever and treat pain or inflammation caused by many conditions, such as headache, toothache, back pain, arthritis, menstrual cramps or minor injury. IBU and/or its metabolites have been detected in aquatic ecosystems (Ashton et al., 2004; Loos et al., 2007; Ternes, 1998), sewage (Lee et al., 2005; Quintana et al., 2005; Verenitch et al., 2006), and drinking water (Loraine and Pettigrove, 2006).

Wastewater treatment plants (WWTP) can act as entrance routes for IBU into the aquatic environment resulting from different sources, including pharmaceutical industries, hospital activities, and human excretion (up to 70\%) (Buser et al., 1999). IBU has been measured in raw wastewater from different sources in amounts ranging from $200 \mathrm{ng} \mathrm{L}^{-1}$ to concentrations $>370 \mu \mathrm{g} \mathrm{L}^{-1}$ (Santos et al., 2007, 2013). In conventional WWTP, IBU is not entirely removed from the wastewater with primary and secondary treatment (Ternes, 1998). Thus, IBU and other micropollutants have received wide attention in the scientific community since the presence of these compounds in the different environmental compartments (soil, water, etc.), even at low concentrations (ranging from ng L ${ }^{-1}$ to $\mathrm{mg} \mathrm{L}^{-1}$ ), can cause harmful environmental and human health effects (Kosonen and Kronberg, 2009; Rodriguez-Narvaez et al., 2017; Verenitch et al., 2006). Moreover, several reports indicate the toxicity of IBU in the aquatic environment. Thus studies have been carried out on acute effects in organisms belonging to different trophic levels (e.g., algae, zooplankton, other invertebrates and fish) (Ortiz de García et al., 2014; Santos et al., 2010). In addition, studies have also addressed the toxic effect of IBU in wastewater treatment system microbial communities in terms of microbial activity (Amariei et al., 2017) and treatment performance, mainly by following the decrease of the capacity to remove organic matter (Falås et al., 2016; Jia et al., 2020) and nitrogen compounds (Pasquini et al., 2013). Considering that

\footnotetext{
* Corresponding author. Centre of Biological Engineering, Universidade do Minho, Campus de Gualtar, 4710-057, Braga, Portugal.

E-mail address: daniela@deb.uminho.pt (D.P. Mesquita).
} 
activated sludge (AS) systems are the most common biological wastewater treatment system found in WWTP worldwide, investigations encompassing IBU effects on microbial aggregate structure are of considerable importance. In this context, extracellular polymeric substances (EPS) clearly play a significant role in AS by contributing to flocculation, settling, dewatering and metal binding (Liu and Fang, 2003; More et al., 2014; Song et al., 2014). EPS also has an important role in protecting aggregated biomass against environmental disturbances (e.g. toxic compounds). Previous studies have investigated the ability of biological processes to degrade IBU under different conditions (Amariei et al., 2017; Zupanc et al., 2013). However, the impact of long-term IBU exposure on EPS production and composition, as well as on the AS floc structure, remains unexplored.

Secretion of EPS by bacteria under pharmaceutical compounds exposure can delay or prevent toxicants reaching microbes (Sheng et al., 2010; Tian et al., 2019). However, it is uncertain how microbial aggregation properties change when exposed to IBU. Therefore, these changes require further investigation, as also their effect on the performance of biological systems. Activated sludge systems (ASS) are often affected by common dysfunctions related to the overproduction of EPS, including zoogleal (or viscous) bulking, making the density of AS aggregates closer to that of the surrounding water, thus decreasing settling ability (Jenkins et al., 2003). Microscopy examination coupled to quantitative image analysis (QIA) is particularly essential in monitoring and controlling ASS. As a result, this technique is becoming widespread for the characterization of the morphology of AS microbial aggregates and the evaluation of AS status. QIA has recently allowed the identification of different types of bulking (Mesquita et al., 2011), demonstrating the usefulness of this methodology as a fast, simple and effective way of detecting deviating conditions in AS.

Taking the above into consideration, the main goal of this study has been to investigate the response of AS to IBU exposure. Additionally, to clarify the EPS protection role towards pharmaceutical compounds, EPS composition and production have been assessed, as well as the properties of the microbial aggregates. We think this work brings new insight into the effects of IBU on AS floc structure (as assessed by QIA methodologies). Moreover, the relationship between the morphology of aggregates and the type and composition of EPS is of major interest and can contribute to timely decisions in AS treating pharmaceutical compounds, which includes IBU.

\section{Materials and methods}

\subsection{SBR set up and operation}

A sequencing batch reactor (SBR) consisting of a $2 \mathrm{~L}$ working volume was operated at room temperature, and the cycle length was $6 \mathrm{~h}$, with $40 \mathrm{~min}$ of feeding, $240 \mathrm{~min}$ of aeration, $40 \mathrm{~min}$ of settling, and $40 \mathrm{~min}$ of withdrawal. For aeration, fine air bubbles were supplied through a porous stone at the bottom of the reactor with a superficial gas velocity of $2.5 \mathrm{~cm} \mathrm{~s}^{-1}$. One litre of a synthetic medium containing mainly acetate as a carbon source and a trace metal solution was added to the feeding phase. The hydraulic retention time was $12 \mathrm{~h}$ with a volumetric exchange ratio of $50 \%$, and the sludge retention time was set at 10 days by discharging daily an appropriate amount $(200 \mathrm{~mL})$ of suspended sludge. SBR was inoculated with AS from a municipal WWTP at an initial concentration of $\sim 3000 \mathrm{mg} \mathrm{L}^{-1}$ of mixed liquor suspended solids (MLSS).

The synthetic wastewater contained the following components (per litre): $1.450 \mathrm{~g}$ sodium acetate $\left(\mathrm{NaCH}_{3} \mathrm{COO} \cdot 3 \mathrm{H}_{2} \mathrm{O}\right), 0.120 \mathrm{~g} \mathrm{NH} \mathrm{Cl}_{4} \mathrm{Cl}, 0.028$ $\mathrm{g} \mathrm{K}_{2} \mathrm{HPO}_{4}, 0.030 \mathrm{~g} \mathrm{MgSO}_{4} .7 \mathrm{H}_{2} \mathrm{O}, 0.07 \mathrm{~g} \mathrm{CaCl}_{2} \cdot 2 \mathrm{H}_{2} \mathrm{O}, 0.015 \mathrm{~g} \mathrm{KCl}$, and $3.5 \mathrm{~mL}$ trace element solution for biomass maintenance (Smolders et al., 1994).

During phase I (day-0 to day-56), the SBR was fed with synthetic wastewater without IBU as a control. From day-57 to day-98 (phase II), IBU (Acros Organics) was added to the synthetic influent media at 10 $\mathrm{mg} \mathrm{L}^{-1}$ for only the first cycle of the day. Lastly, from day-99 onwards (phase III), the reactor was operated containing $5 \mathrm{mg} \mathrm{L}^{-1} \mathrm{IBU}$, following the same operational procedure as in phase II. Phases I, II, and III were sequentially conducted, in which the system was re-inoculated with new biomass to eliminate the effects caused by adding IBU to the system. Prior to each experiment, the inoculated biomass was acclimatized for a period of 20 days to the synthetic media without IBU exposure.

IBU was selected due to its widespread occurrence in WWTP (Sanganyado et al., 2017), suspicion of its causing dysfunction in AS at the selected concentrations (Pasquini et al., 2013), and the lack of knowledge of ASS reliability in the case of irregular exposures (Abegglen et al., 2009; Langenhoff et al., 2013). In small or decentralized wastewater treatment systems, high load variations of micropollutants are expected (higher by a factor of 50-1000 than in centralized treatment) due to irregular consumption (e.g., medication by individuals), and these concentrations can be found in the effluents from hospitals and elderly houses.

\subsection{Analytical methods}

Chemical oxygen demand (COD), ammonium $\left(\mathrm{NH}_{4}^{+}\right)$, nitrite $\left(\mathrm{NO}_{2}^{-}\right)$, and nitrate $\left(\mathrm{NO}_{3}^{-}\right)$concentrations were determined with cell tests on a Hach Lange DR 5000 spectrophotometer (Hach Lange, Dusseldorf, Germany).

Mixed liquor volatile suspended solids (MLVSS), MLSS, and the sludge volume index (SVI) of a sludge sample were measured according to the Standard Methods (APHA, 1998). The sludge suspension was settled for $30 \mathrm{~min}$, after which the supernatant fraction was collected and measured as effluent suspended solids (ESS). This ESS level indicates the microbial flocculation performance, whereas the SVI value specifies the sludge settleability and compressibility.

IBU (in samples collected from the influent and effluent SBR) was assayed as previously described (Quintelas et al., 2020).

\subsection{EPS extraction and quantification}

A heat extraction method (Li and Yang, 2007) was modified to extract the loosely bound EPS (LB-EPS) and tightly bound EPS (TB-EPS) from AS. A sludge suspension was first dewatered by centrifugation ( $5810 \mathrm{R}$, Eppendorf) in a $40 \mathrm{~mL}$ tube at $8000 \mathrm{~g}$ for $5 \mathrm{~min}$. The sludge pellet in the tube was resuspended at its original volume of $40 \mathrm{~mL}$ with $100 \mathrm{mM} \mathrm{NaCl}$ solution with a similar salinity to the SBR reactor solution. $\mathrm{The} \mathrm{NaCl}$ solution for dilution was preheated to $70^{\circ} \mathrm{C}$ to ensure that the sludge suspension immediately reached $50^{\circ} \mathrm{C}$. Without delay, the sludge suspension was sheared with a vortex mixer for $1 \mathrm{~min}$, followed by centrifugation at $4000 \mathrm{~g}$ for $10 \mathrm{~min}$. The organic matter in the supernatant was readily extractable EPS, regarded as the biomass's LB-EPS. For TB-EPS extraction, the sludge pellet left in the centrifuge tube was re-suspended in $100 \mathrm{mM} \mathrm{NaCl}$ solution to its original volume of $40 \mathrm{~mL}$. The sludge suspension was heated to $60^{\circ} \mathrm{C}$ in a water-bath for $30 \mathrm{~min}$, and the mixture was then centrifuged at $12,000 \mathrm{~g}$ for $20 \mathrm{~min}$ at $4{ }^{\circ} \mathrm{C}$. The supernatant collected was regarded as the TB-EPS extraction of the sludge. All supernatant samples were filtered through a $0.45 \mu \mathrm{m}$ acetate cellulose membrane.

Both the LB-EPS and TB-EPS extractions were analysed for polysaccharides (PS), proteins (PN) and humic acid substances (HAS). PN and HAS were analysed in triplicate in an UV/VIS spectrophotometer (DR 500 Hach Lange, Dusseldorf, Germany), following the modified Lowry method using bovine serum albumin (BSA) and humic acid as standards, respectively. The PS content was determined in duplicate by the anthrone-sulphuric acid method, using glucose as the standard (Frolund et al., 1995). The sum of PN, HAS and PS content was referred to as the total LB-EPS and TB-EPS. The sum of LB-EPS and TB-EPS was also assessed as the total EPS. 


\subsection{Image acquisition, processing, and analysis}

For the QIA analysis, a $2 \mathrm{~mL}$ sample was taken from the middle depth of the SBR during the aeration phase. Images were acquired in triplicate of $10 \mu \mathrm{L}$ air-dried slides through bright-field microscopy with an Olympus BX51 microscope (Olympus, Shinjuku, Japan) at $40 \times(1360 \times$ 1024 pixels) and 8-bits, coupled to an Olympus DP72 camera (Olympus, Tokyo, Japan), giving us 150 images per day. The images used for the characterization of aggregates and filaments content were processed by a program developed in Matlab 9.2 (The Mathworks, Inc., Natick, USA) by Amaral and Ferreira (2005). Image processing and analysis information can be found in the supplementary information (SI, Figure S1).

The aggregates and filaments content were measured in terms of the total area per sample volume (TA/Vol), the total filament length per sample volume (TL/Vol), and the total filaments length per MLSS (TL/ MLSS). The aggregates size (in equivalent diameter, Deq) was also determined. Aggregates were divided into 3 size classes according to their Deq: small $(<25 \mu \mathrm{m})$, intermediate $(25-250 \mu \mathrm{m})$, and large $(>250$ $\mu \mathrm{m})$. The aggregate area percentage (\%Area) was also determined for the small (sml), intermediate (int), and large (larg) aggregates. These parameters proved adequate for monitoring settling dysfunctions in conventional ASS, as by Mesquita et al. (2011).

\subsection{Statistical analysis}

Statistical analysis was used for phase I (17 samples), phase II (17 samples), and phase III (23 samples), and the results are given as mean and one standard deviation.

Significant differences were determined by analysis of variance (ANOVA), using Tukey's post-hoc test in SPSS 26.0 to verify whether there was a significant difference in the removal of $\mathrm{COD}, \mathrm{NH}_{4}^{+}$and IBU between the 3 phases, and to investigate whether there were differences in the concentration of EPS and its components.

Spearman rank-order correlation coefficient was used to identify the strength of the relationship between EPS and its components and ESS, SVI, and QIA parameters. The values of the correlation coefficients vary
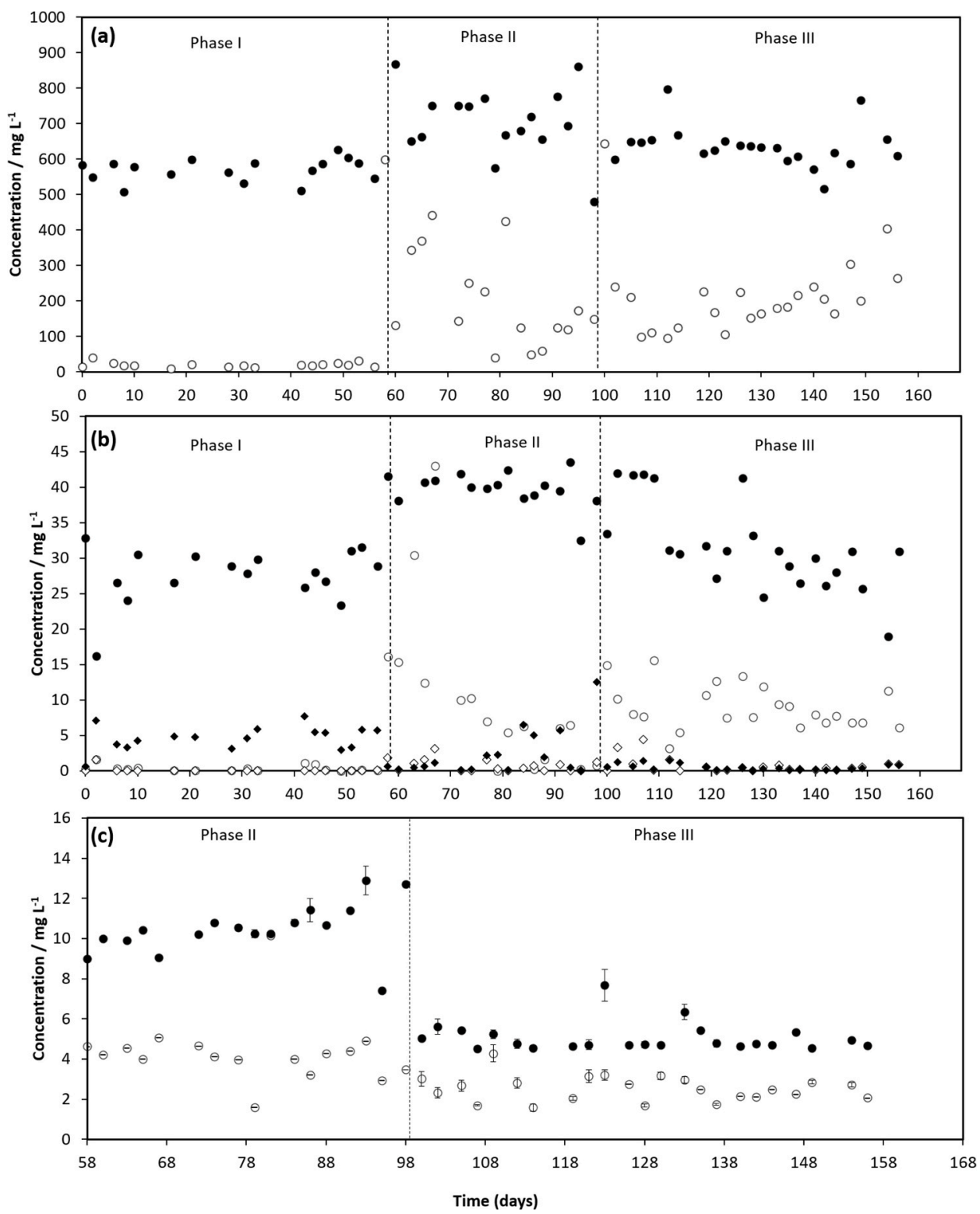

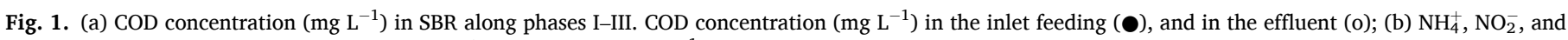

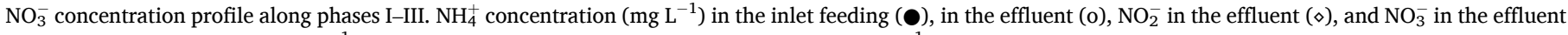
$(\diamond)$; (c) IBU concentration ( $\mathrm{mg} \mathrm{L}^{-1}$ ) in SBR along phases II and III. IBU concentration ( $\mathrm{mg} \mathrm{L}^{-1}$ ) in the inlet feeding ( $)$ and in the effluent (o). 
between +1.00 and -1.00 . Both extremes represent perfect relationships between the variables, and 0.00 indicates no relationship.

\section{Results}

\subsection{SBR performance}

Through phase I, the effluent COD was $<40 \mathrm{mg} \mathrm{L}^{-1}$ (Fig. 1a), which means that COD removal efficiency was stable and reached an average of 96\% (SI - Table S1). With IBU (phase II), the effluent COD ranged from 40 to $600 \mathrm{mg} \mathrm{L}^{-1}$, and from 95 to $646 \mathrm{mg} \mathrm{L}^{-1}$ in phase III, where the COD average removal efficiency decreased on average to 71 and $65 \%$, respectively (SI - Table $\mathrm{S} 1$ ).

Ammonium ions $\left(\mathrm{NH}_{4}^{+}\right)$were almost completely oxidized in phase I, with concentrations in the effluent of $<1.6 \mathrm{mg} \mathrm{L}^{-1}$ (Fig. 1b), and therefore removal efficiencies of $99 \%$ were obtained (SI - Table S1). In phases II and III, higher $\mathrm{NH}_{4}^{+}$effluent concentrations (Fig. 1b) and accordingly lower removal efficiencies (SI - Table S1) of 77 and $71 \%$ were obtained, respectively. Nitrite $\left(\mathrm{NO}_{2}^{-}\right)$concentrations remained almost unchanged throughout the experiments (Fig. 1b) due to rapid transformation to nitrate $\left(\mathrm{NO}_{3}^{-}\right)$. However, $\mathrm{NO}_{2}^{-}$concentration increased on average from $0.1 \mathrm{mg} \mathrm{L}^{-1}$ during phase I to $0.7 \mathrm{mg} \mathrm{L}^{-1}$ during phase II and III (SI - Table S1). Regarding effluent $\mathrm{NO}_{3}^{-}$concentration (Fig. 1b), a decreasing trend occurred throughout the entire experiment, with higher concentrations being obtained in the absence of IBU (phase I), ranging from around 7 to $3 \mathrm{mg} \mathrm{L}^{-1}$. On average, effluent $\mathrm{NO}_{3}^{-}$concentration was $4.6 \mathrm{mg} \mathrm{L}^{-1}$ in phase I, i.e. twice the concentration for phase II and 10 fold the concentration obtained for phase III (SI - Table S1).

Statistical results (ANOVA and Tukey HSD test) also indicated that $\mathrm{COD}$ and $\mathrm{NH}_{4}^{+}$removal efficiencies were significantly different in phase I from both phase II and III (SI - Table S2 and S3). IBU at concentrations of 10 and $5 \mathrm{mg} \mathrm{L}^{-1}$ significantly affected $(\mathrm{p}<0.05)$ the metabolism of heterotrophic microorganisms, ammonia-oxidizing bacteria (AOB) and nitrite-oxidizing bacteria (NOB), with a decrease of both organic matter removal and ammonia oxidation.

The ability of the biomass to remove IBU from the liquid phase was also investigated, and effluent IBU concentrations of $<5 \mathrm{mg} \mathrm{L}^{-1}$ (phase II) and $4 \mathrm{mg} \mathrm{L}^{-1}$ (phase III) were achieved (Fig. 1c). Consequently, average removal efficiencies of 58 and $50 \%$ were accomplished (SI Table S1). In this case, statistical results indicated that IBU removal efficiencies were not significantly different between phase II and III (SI Tables S2 and S3).

\subsection{Effect of ibuprofen on EPS production and composition}

The phase I experiment had an average LB-EPS content of $138.30 \mathrm{mg}$ EPS/g MLVSS, whereas phase II had an average of $20.02 \mathrm{mg}$ EPS $/ \mathrm{g}$ MLVSS, and phase III $38.92 \mathrm{mg}$ EPS/g MLVSS (Fig. 2a, SI - Table S4), indicating that LB-EPS content decreased as IBU concentration increased, which suggests a negative action on LB-EPS content production. Accordingly, LB-EPS content was significantly different $(\mathrm{p}<0.05)$ in phase I (SI - Tables S5 and S6). Regarding TB-EPS content, similar results were obtained with phase I and II (average of $88.49 \mathrm{mg}$ EPS $/ \mathrm{g}$ MLVSS and $92.37 \mathrm{mg}$ EPS/g MLVSS, respectively), and a lower content during phase III (average 39.16 mg EPS/g MLVSS) (Fig. 2a, SI -Table S4), thus showing a significant $(\mathrm{p}<0.05)$ difference between only phase II and phase III (SI - Tables S5 and S6).

Regarding LB-EPS content, HAS represented 53 and $58 \%$ for phase I and III, respectively, followed by PN (with 41 and 36\%, respectively), and PS at a small proportion (6\%) for both phases (Fig. 2b, SI - Table S4). PN was the larger component in phase II, representing on average $50 \%$, followed by HAS and PS (averages of 43 and 7\%, respectively; Fig. 2b, SI - Table S4). A significant difference $(p<0.05)$ was recorded for PS, PN, and HAS in the presence of IBU. Nevertheless, the content of PS, PN and HAS did not change significantly $(\mathrm{p}<0.05)$ between phase II and phase III (SI - Tables S5 and S6).
TB-EPS components showed the same behaviour with LB-EPS components (Fig. 2c). Although TB-EPS components concentration changed in all phases, no significant difference $(\mathrm{p}<0.05)$ was found for PS (SI Tables S5 and S6). A significant difference was obtained for HAS just between phase I and phase III. PN gave the highest content when IBU has been added in phase II (Fig. 2c, SI - Table S4), and its significant increase $(\mathrm{p}<0.05)$ (SI - Tables S5 and S6) could probably be explained as a strategy of microorganisms defence against harsh conditions (Kong et al., 2017; Zhou et al., 2019). For phase III, a decrease in TB-EPS occurred compared with phase I, suggesting that IBU directly interferes with AS metabolic activity - similar results had been obtained by Pasquini et al. (2013) when concentrations varying from 0.1 to $5 \mathrm{mg} \mathrm{L}^{-1}$ were tested, and a reduction in the TB-EPS production was also observed.

\subsection{Settling ability and morphological properties}

The aggregate area distribution analysis clarifies the nature of aggregates within the biomass (Fig. 3). During phase I, there was an
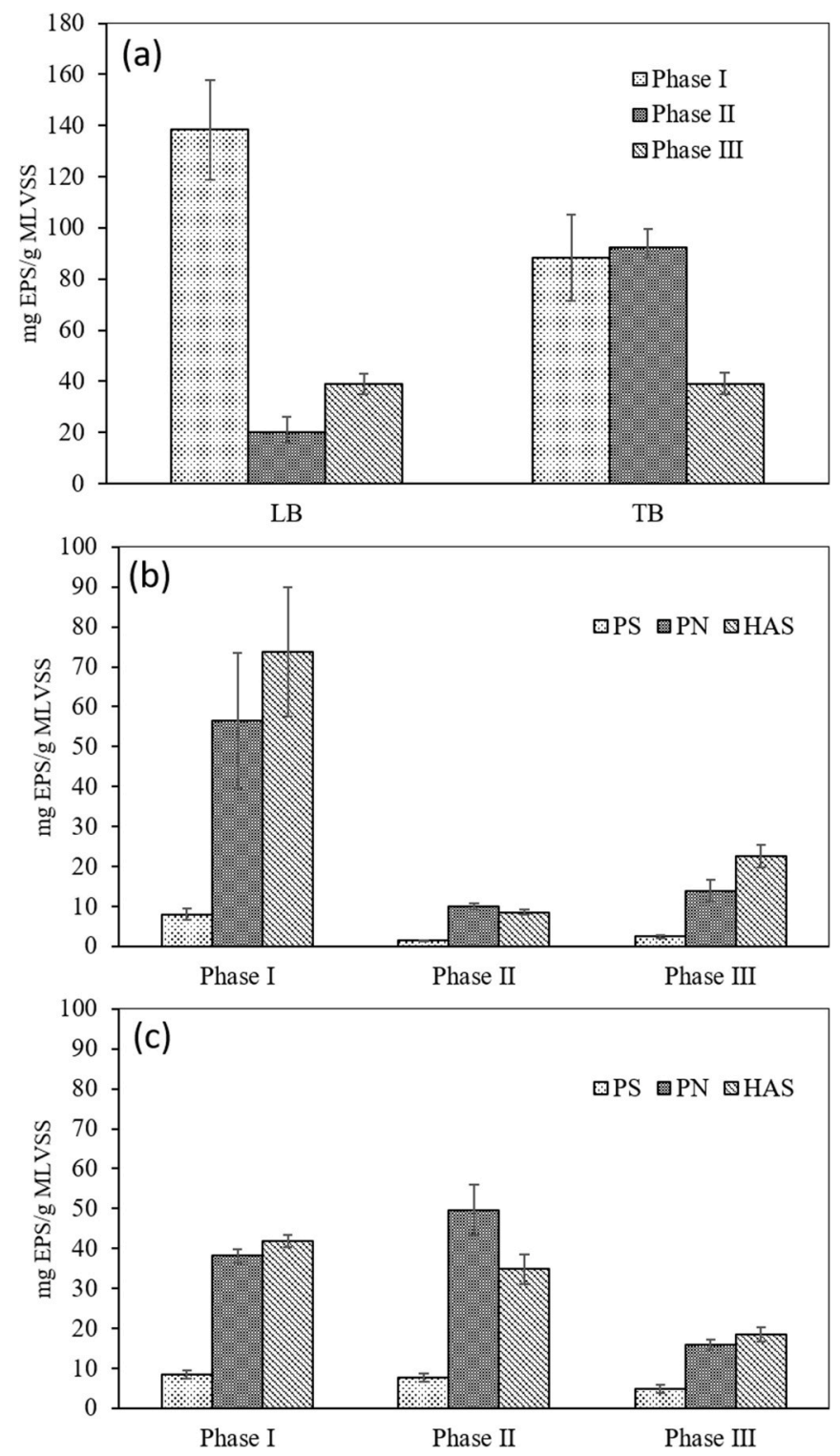

Fig. 2. (a) LB-EPS and TB-EPS for different phases of SBR operation. Quantities of LB-EPS and TB-EPS in terms of PS, PN, and HAS content; (b) PS, PN, and HAS content of the LB-EPS; (c) PS, PN, and HAS content of the TB-EPS. 


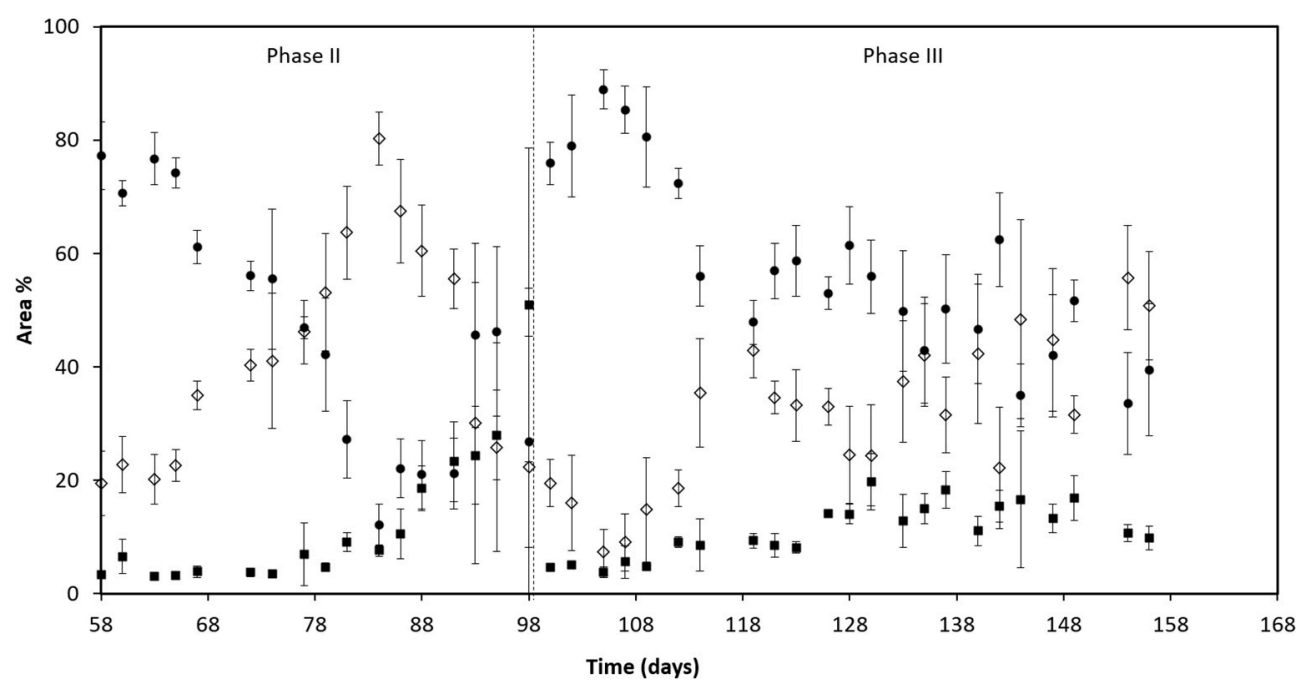

Fig. 3. Area percentage along phases II and III for small aggregates ( $\square$ ); intermediate (๑); and large aggregates ( $\diamond)$.

expected predominance of intermediate aggregates and residual percentages of large aggregates (data not shown), agreeing with the results of Mesquita et al. (2011). The significant presence of intermediate aggregates (\%Area ${ }_{\text {int }}$ ranging from 77 to $47 \%$ ) until day 77 of phase II (despite the decreasing trend), concerning the small (\%Area sml $_{\text {ranging }}$ from 3 to $7 \%$ ) and large aggregates (\%Area $a_{\text {larg }}$ ranging from 20 to 46\%), indicated the predominance of normal aggregates structures. From day 77 until day 91, there was a predominance of large aggregates in the system (\%Area $a_{\text {larg }}$ of $\sim 61 \%$ on average). These results are also associated at this point to the sharp increase of both MLSS (from 2.3 to $4.5 \mathrm{~g}$ $\mathrm{L}^{-1}$ ) and TA/Vol (from 2.6 to $9.2 \mathrm{~mm}^{2} \mu \mathrm{L}^{-1}$ ) in the same period of operation (data not shown), previously reported as commonly coupled to the growth of large aggregates (Mesquita et al., 2011). From day 84 onwards, the aggregates were accompanied by a significant number of protruding filaments as visualized by microscopy (SI - Figure S2c, d), disturbing the image acquisition process.

In phase III, aggregate area distribution analysis showed the same trend as phase II for intermediate and large aggregates, although large aggregates were never predominant in the biological system throughout the experimental period (with the exception of the last samples). A decrease in intermediate aggregates (\%Area ${ }_{\text {int }}$ from 88 to $45 \%$ ) and an increase in the large aggregates (\%Area $a_{\text {arg }}$ from 7 to 43\%) occurred from day 105 to day 119, pointing to a global trend to form larger structures (Fig. 3). This behaviour was accompanied by a sharp decrease of MLSS (from 3.3 to $1.7 \mathrm{~g} \mathrm{~L}^{-1}$ ), indicating a washout phenomenon and a minor decrease of TA/Vol (from 2.6 to $2.0 \mathrm{~mm}^{2} \mu \mathrm{L}^{-1}$ ) in the same period of operation (data not shown) due to the representation of large aggregates in the system. Despite this abrupt change, from day 119 until the end of phase III, and in general, intermediate aggregates dominated in the biological system (\%Area int $_{\text {of }} \sim 49 \%$ on average), with a high contribution of large aggregates (\%Area $\mathrm{a}_{\text {larg }}$ of $\sim 37 \%$ on average). Again, microscopy showed that the aggregates were accompanied by a significant proliferation of protruding filaments (SI - Figure S3c, d).

The SVI results during phase I were consistently lower than $150 \mathrm{~mL}$ $\mathrm{g}^{-1}$ (data not shown), the threshold for filamentous bulking, as proposed by Jenkins et al. (2003). In the presence of IBU, and at the beginning of phase II and III, the SVI values (Fig. 4) were lower or close to the threshold considered for filamentous bulking, where combining this information with microscopic inspection (SI - Figure S2a and S3a) excluded this phenomenon. TL/Vol and the TL/MLSS were also included in this evaluation due to their importance in predicting the SVI (Amaral and Ferreira, 2005). Accordingly, the presence of a filamentous bulking condition was established for values $>10 \mathrm{~mm} \mathrm{\mu L}^{-1}$ for TL/Vol and $>10$, $000 \mathrm{~mm} \mathrm{mg}^{-1}$ for TL/MLSS (Jenkins et al., 2003; Amaral and Ferreira, 2005). Regarding Fig. 4, the values obtained for TL/Vol and TL/MLSS at the beginning of phase II and phase III were lower than the established limits. QIA results corroborated a bulking problem (Fig. 4) from day 84 until the end of phase II (TL/MLSS of $\sim 46,000 \mathrm{~mm} \mathrm{mg}^{-1}$, and TL/Vol of

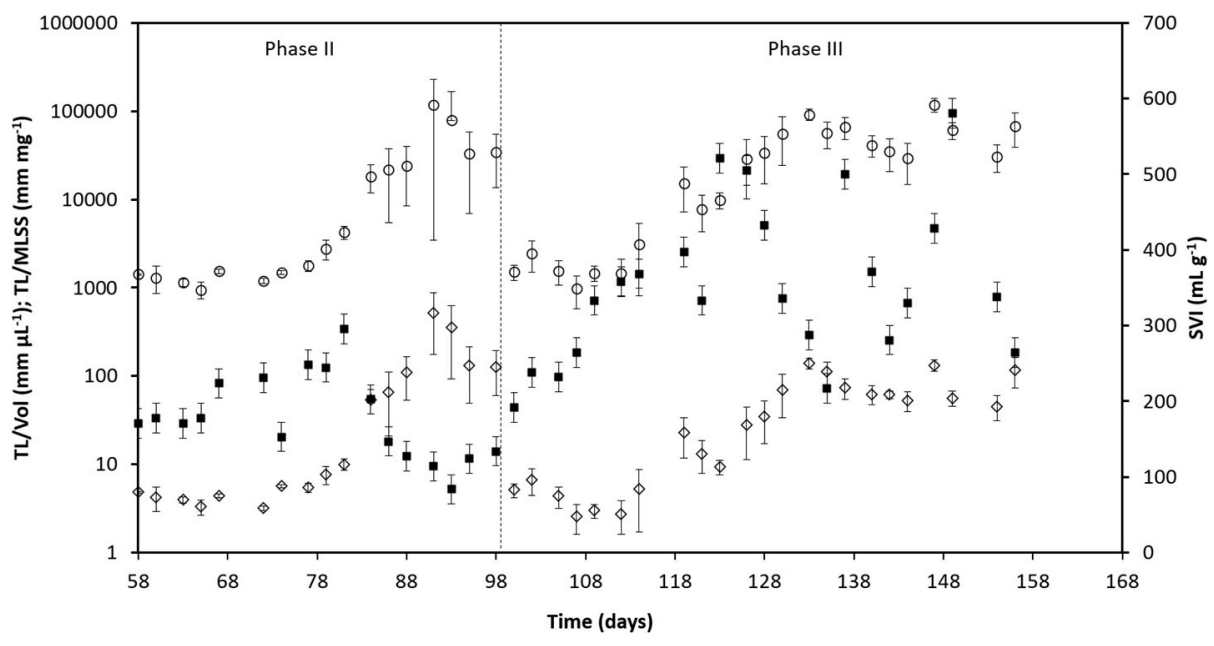

Fig. 4. Experimental profile of TL/Vol $(\diamond)$; TL/MLSS (o); and SVI ( $\square$ ) along phases II and III. 
$\sim 195 \mathrm{~mm} \mu \mathrm{L}^{-1}$ on average), and from day 119 until the end of phase III

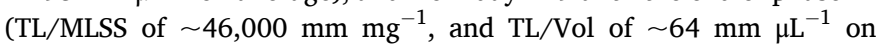
average).

Statistical analysis based on Spearman's correlation coefficients between SVI, ESS, EPS composition, and image analysis parameters during phases II and III, are shown in Fig. 5. The heat map shows positive correlation in the blue gradient and negative correlation in the red gradient between these variables. In the supplementary material (SI Tables S7 and S8), it is possible to observe the specific values of Spearman's correlation coefficients and their corresponding p-values.
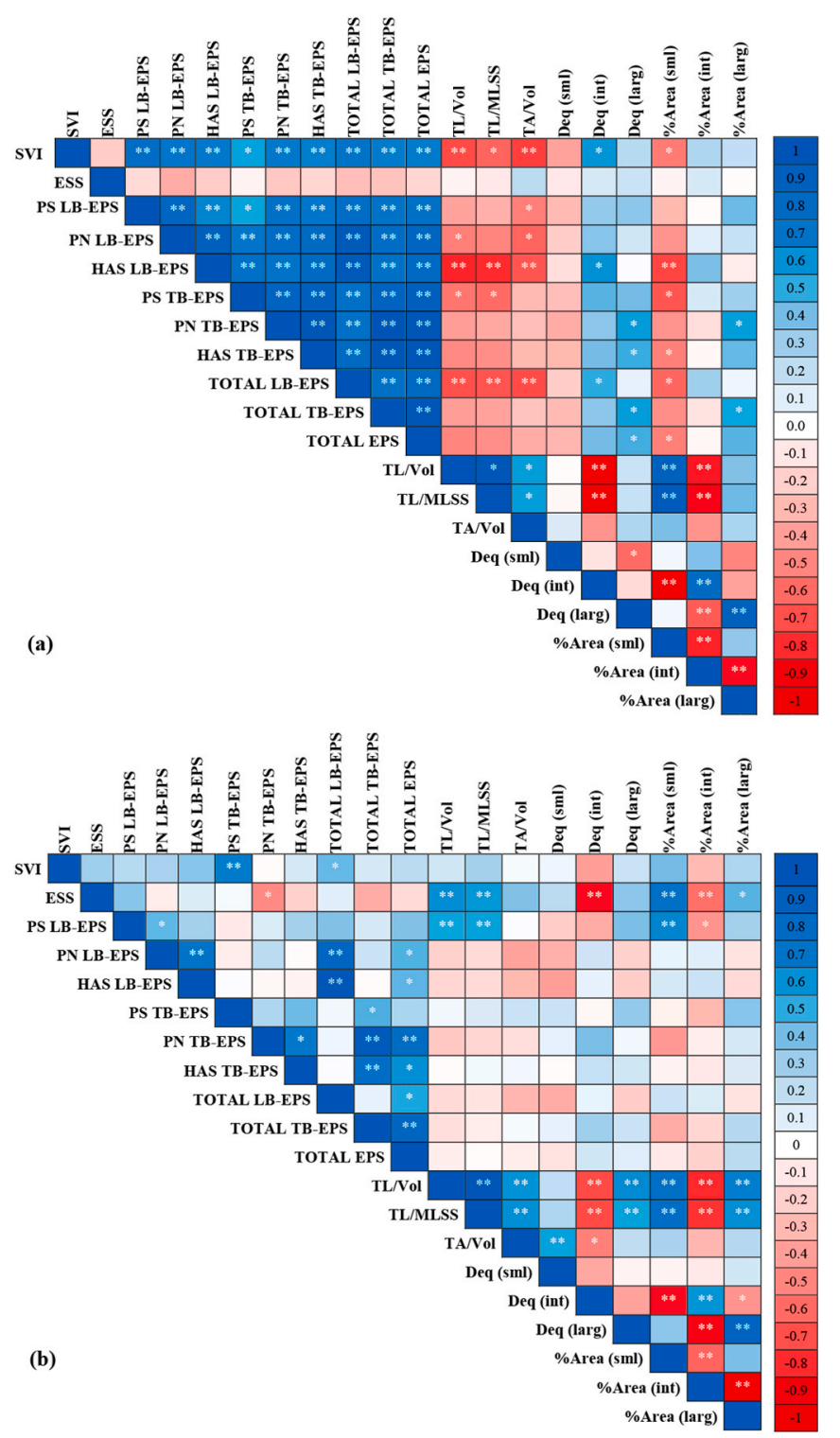

Fig. 5. Heat map of Spearman correlation coefficients computed between SVI, ESS, EPS composition, and morphological parameters during (a) phase II ( $\mathrm{n}=$ $17)$ and (b) phase III $(n=23)$. The values of correlation coefficients and directions are displayed according to the colour key: positive correlations as blue gradients from 0 to 1 and negative correlations as red gradients from 0 to -1 . Significance of $\mathrm{p}$-values are as followed: $\mathrm{p}<0.01$ represented as $* *$, and $\mathrm{p}<$ 0.05 represented as *. (For interpretation of the references to colour in this figure legend, the reader is referred to the Web version of this article.)

\section{Discussion}

\subsection{SBR performance}

We have found that the removal efficiencies of $\mathrm{COD}$ and $\mathrm{NH}_{4}^{+}$during phases with IBU feeding decreased significantly compared with the control phase without IBU feeding, indicating that the selected IBU concentration significantly inhibits SBR biomass activity. Accumulation of $\mathrm{NO}_{2}^{-}$and the decrease of $\mathrm{NO}_{3}^{-}$during phases II and III also indicated that IBU disturbs the biomass in the nitrification process. These findings are consistent with previous works that gave similar removal data for both COD and $\mathrm{NH}_{4}^{+}$, where SBR systems operated in the presence of 5 and $1 \mathrm{mg} \mathrm{L}^{-1}$ IBU (Pasquini et al., 2013; Jia et al., 2020). Additionally, similar results of $\mathrm{NO}_{3}^{-}$accumulation were seen by Roh et al. (2009) in a nitrifying ASS with IBU exposure. Accordingly, it seems reasonable to infer that IBU is responsible for dysfunction in nitrification, hindering both AOB and NOB activity.

The removal efficiencies achieved during these investigations agree with those obtained in the operation of an SBR with AS during treatment with $500 \mu \mathrm{g} \mathrm{L}^{-1}$ IBU (Peng et al., 2019). Moreover, IBU removal in ASS has been shown to be particularly influenced by the microbial community in the system (Men et al., 2017; Peng et al., 2019). Additionally, once a long-term exposure to IBU triggers the development of IBU degrading microorganisms (CY et al., 2020; Zhou et al., 2019), one can explain the higher biodegradation ability of IBU in phase II $\left(10 \mathrm{mg} \mathrm{L}^{-1}\right)$. Many investigations show the role of heterotrophic and AOB from ASS in degrading IBU; these reports suggest that AOB is not involved in IBU biodegradation, and it seems that heterotrophic microorganisms play a crucial role in IBU biodegradation (Jia et al., 2020; Roh et al., 2009; Men et al., 2017).

\subsection{Effect of ibuprofen on EPS production and composition}

During phases II and III, IBU affected the biomass by varying the amount of EPS produced. Increase of TB-EPS content in phase II (Fig. 2b) may be assigned to the high relative abundance of large aggregates related to the overproduction of EPS (An et al., 2016; Zhang et al., 2019). For phase III, a decrease in TB-EPS occurred compared with phase I, suggesting that IBU directly interferes with AS metabolic activity (Fig. 2b). Similar results were reported by Pasquini et al. (2013) with concentrations varying from 0.1 to $5 \mathrm{mg} \mathrm{L}^{-1}$, and a reduction in the TB-EPS production was also seen. There was a trend regarding the EPS components concerning the concentration of HAS $>$ PN $>$ PS for phases I and III, and for phase II of PN > HAS > PS. Previously it has been suggested that PN and PS are the major components of EPS (Frølund et al., 1996); however, more recent work has found greater amounts of PN and HAS in biological systems (Oliveira et al., 2020; Wilén et al., 2003). Indeed, different designs and operational conditions of AS result in different EPS levels. The EPS composition difference can also be attributed to the type of extraction procedure (which strongly affects the yield) and the quantification method to evaluate the extracted EPS chemical composition.

In the presence of toxic substances, an increase in EPS production can be considered as a defence mechanism for microorganisms. Accordingly, Zhou et al. (2019) found an increase in EPS production for IBU at levels varying from 1 to $5 \mathrm{mg} \mathrm{L}^{-1}$. However, some toxic substances inhibit EPS production; Badireddy et al. (2008) found a significant reduction of EPS when Brevundimonas diminuta was exposed to bismuth dimercaptopropanol. Besides, the proportion of PN/PS, which is generally used to indicate hydrophobicity, had a higher value $(\mathrm{PN} / \mathrm{PS}=6.4)$ for phase II compared to the other two phases (PN/PS $=4.3$ for phase I and PN/PS $=$ 2.9 for phase III), suggesting stronger hydrophobicity and the possibility of having more sites for IBU adsorption (Zhang et al., 2019). 


\subsection{Settling ability and morphological properties}

Throughout phase II and III, SVI were $>150 \mathrm{~mL} \mathrm{~g}^{-1}$ and the existence of low sludge settling ability properties with the development of protruding filamentous bacteria (SI - Figures S2 and S3) has been verified. These results agree with previous studies reporting bulking problems and morphological dysfunctions in ASS (Amaral and Ferreira, 2005; Mesquita et al., 2011). Interestingly, SVI values at the end of phase II decreased to $<150 \mathrm{~mL} \mathrm{~g}^{-1}$, despite the larger values of $\mathrm{TL} / \mathrm{Vol}$ and TL/MLSS. This can be attributed to the presence of intermediate and large structures that can settle well, despite their poor structure (combined with high amounts of protruding filaments SI - Figure S2c, d). Thus, this is a clear indicator that other factors, such as chemical make-up or colloidal properties, are important in the settling of sludge, as well as EPS composition (Wilén et al., 2008), which will be further discussed. At the end of phase II the biomass was no longer accurately assessed by QIA, and thus the long-term IBU exposure at $10 \mathrm{mg} \mathrm{L}^{-1}$ led to ASS collapse. On the other hand, at the end of phase III, SVI was always higher than the threshold limit, even with a balance of intermediate and large aggregates in the system, demonstrating the strong influence of protruding filamentous bacteria in reducing the sludge settling ability (SI - Figure S3c, d).

Spearman's correlation coefficients were used to further investigate the relationship between SVI, ESS, EPS composition, and image analysis parameters during phases II and III. As previously observed during phase II, high quantities of TB-EPS were obtained, especially PN, which suggest that chemical properties change in the surface of AS. Thus, these variations in EPS may also have influenced the SVI results rather than QIA parameters (as shown in Fig. 5a). Furthermore, a slight increase in the ESS during phase II occurred. It is likely that large and intermediate aggregates settle faster than small aggregates, which may contribute to the decrease in SVI. The faster settling of the larger flocs associated with a higher concentration of MLSS could also contribute to the low SVI values at the end of phase II (Fig. 4).

Our results suggest that EPS and its components influence the structure of the aggregates. For phase II, a significant positive correlation was found between intermediate aggregates and HAS LB-EPS and Total LB-EPS (Fig. 5a and SI - Table S7). A trend to large aggregates formation and aggregates with large amounts of filaments was seen that suggest an open floc structure with poor compressibility (SI - Fig. S2) (Jin et al., 2003). Large aggregate formation can be associated with the high levels of biopolymers produced by biomass since they were positively correlated with the PN-TB, HAS-TB, TB-EPS, and total EPS quantity (Fig. 5a and SI - Table S7). Thus, these results indicate that intermediate and large aggregates contain higher EPS concentrations than small aggregates. Oliveira et al. (2020) also observed that EPS had a significant effect on the size distribution of aerobic granular sludge in a full-scale WWTP, with small granules being positively correlated to PN concentration in EPS.

The results suggest that during phase III, the PN TB-EPS level probably had a greater significantly negative influence than other EPS contents regarding dysfunction in bioflocculation (ESS) of the biomass (Fig. 5b and SI - Table S8). PN impacted bioflocculation since they are mainly created by hydrophobic $\mathrm{R}$ groups in amino acids promoting flocculation. PN proved to be the main factor determining the aggregation ability of anammox (Hou et al., 2015). PN was also found to play a crucial role in granule formation and stability (McSwain et al., 2005). Higgins and Novak (1997) found that microbial aggregates tend to deflocculate after removing their surface PN. No correlation was found between image analysis parameters and LB-EPS and TB-EPS for phase III (Fig. 5b and SI - Table S8). Nevertheless, a positive correlation was seen only between PS LB-EPS and \%Area of small aggregates. A negative correlation was seen between PS LB-EPS and \%Area of intermediate aggregates, suggesting that PS in the EPS influenced the microbial aggregation properties (Higgins and Novak, 1997).

Due to their physicochemical properties, EPS are involved in microbial aggregates structure through complex interactions, which make this biopolymer bond electrostatically and physically to microbial surfaces. However, there is evidence suggesting that the influence of individual EPS components on microbial aggregates flocculation is complex (Chen et al., 2007; McSwain et al., 2005; Wilén et al., 2008; Hou et al., 2015). Therefore, can be supposed that IBU at $10 \mathrm{mg} \mathrm{L}^{-1}$ creates a greater change in the aggregates' structure, instead of IBU at 5 $\mathrm{mg} \mathrm{L}^{-1}$. Regarding Fig. $5 \mathrm{a}$ and $\mathrm{b}$, these changes may be associated with the high production of EPS, especially TB-EPS. The correlations suggest that EPS and its components significantly influence aggregates parameters. These findings agree with those of Quintelas et al. (2020), showing that a change in the biomass structure occurs when IBU is added at 1,10 , and $20 \mathrm{mg} \mathrm{L}^{-1}$.

Fig. 5 and SI - Tables S7 and S8, show that EPS and their components (PS, PN, and HAS) have a critical role in the sludge settleability than the aggregates' morphological structure. The results of our research agree with previous studies demonstrating a positive relationship between SVI content and the content of LB-EPS and TB-EPS (Li and Yang, 2007; Liao et al., 2011). However, the effects of the main components of EPS on the sludge settleability remain unclear, and the results were inconsistent with previous studies. Martinez et al. (2000) found that SVI content increased with the PN EPS content, whereas Jin et al. (2003) reported that the quantities of PN and PS in EPS were significantly correlated with the SVI, which is in accordance with the results we have obtained. According to Liao et al. (2011), EPS can differ in molecular weight and composition, mainly when produced under different conditions by microorganisms in biological systems. Thus, the difference in the concentration EPS components (PS, PN, and HAS) might explain the AS difference in settleability behaviour between phases II and III.

\section{Conclusions}

We have shown that a significant reduction in heterotrophic bacteria activity occurs, with reduced COD removal efficiency and substantial inhibitory effect in the nitrification process, when AS is exposed to IBU during phases II and III. Regarding the removal of IBU in the liquid phase, a reduction in the concentration of 58 and $50 \%$ for phases II and III, respectively, was achieved.

A decrease of LB-EPS concentration occurred with increasing IBU concentration. The higher concentration of PN in phase II may be associated with a greater impact on the microbial composition due to the introduction of IBU at $10 \mathrm{mg} \mathrm{L}^{-1}$. The results of PN concentrations and the increase in the PN/PS ratio indicate that PN greatest production in TB-EPS was probably for cellular protection against IBU. EPS plays a significant role in sludge properties, and a significant correlation ( $\mathrm{p}<$ 0.05) was found between SVI and all EPS contents for phase II, which may be associated with a major change in the biomass structure. For phase III, bioflocculation had a significant negative correlation ( $\mathrm{p}<$ 0.05 ) with PN LB-EPS, and a significant positive correlation was found for sedimentation, $(\mathrm{p}<0.01)$ with PS TB-EPS and $(\mathrm{p}<0.05)$ with total LB-EPS.

Finally, QIA gave some insight into the changes in the biomass structure correlating well with EPS components. This relationship demonstrates that both LB-EPS and TB-EPS and/or their components (PS, PN, HAS) significantly influence the microbial aggregates' structure.

\section{Credit author statement}

António Melo: Investigation, Formal analysis, Writing - original draft. Joana Costa: Investigation, Software, Formal analysis. Cristina Quintelas: Investigation, Formal analysis, Writing - review \& editing. Eugénio C. Ferreira: Supervision, Writing - review \& editing, Funding acquisition. Daniela P. Mesquita: Conceptualization, Supervision, Writing - review \& editing. 


\section{Declaration of competing interest}

The authors declare that they have no known competing financial interests or personal relationships that could have appeared to influence the work reported in this paper.

\section{Acknowledgments}

The authors thank the Portuguese Foundation for Science and Technology (FCT) under the scope of the strategic funding of UIDB/ $04469 / 2020$ unit. The authors also acknowledge the financial support to António Melo through the grant number 240-20170220 provided by Instituto Federal de Educação, Ciência e Tecnologia de Pernambuco (IFPE). Daniela P. Mesquita and Cristina Quintelas thank FCT for funding through program DL 57/2016 - Norma transitória. The final proofreading of this manuscript was carried out by BioMedES UK. (ww. biomedes.biz).

\section{Appendix A. Supplementary data}

Supplementary data to this article can be found online at https://doi. org/10.1016/j.jenvman.2021.112852.

\section{References}

Abegglen, C., Joss, A., McArdell, C.S., Fink, G., Schlüsener, M.P., Ternes, T.A., Siegrist, H., 2009. The fate of selected micropollutants in a single-house MBR. Water Res. 43, 2036-2046. https://doi.org/10.1016/j.watres.2009.02.005.

Amaral, A.L., Ferreira, E.C., 2005. Activated sludge monitoring of a wastewater treatment plant using image analysis and partial least squares regression. Anal. Chim. Acta 544, 246-253. https://doi.org/10.1016/j.aca.2004.12.061.

Amariei, G., Boltes, K., Rosal, R., Letón, P., 2017. Toxicological interactions of ibuprofen and triclosan on biological activity of activated sludge. J. Hazard Mater. 334, 193-200. https://doi.org/10.1016/j.jhazmat.2017.04.018.

An, W., Guo, F., Song, Y., Gao, N., Bai, S., Dai, J., Wei, H., Zhang, L., Yu, D., Xia, M., Yu, Y., Qi, M., Tian, C., Chen, H., Wu, Z., Zhang, T., Qiu, D., 2016. Comparative genomics analyses on EPS biosynthesis genes required for floc formation of Zoogloea resiniphila and other activated sludge bacteria. Water Res. 102, 494-504. https:// doi.org/10.1016/j.watres.2016.06.058.

APHA, 1998. Standard Methods for the Examination of Water and Wastewater, twentieth ed. American Public Health Association, Washington, DC.

Ashton, D., Hilton, M., Thomas, K.V., 2004. Investigating the environmental transport of human pharmaceuticals to streams in the United Kingdom. Sci. Total Environ. 333, 167-184. https://doi.org/10.1016/j.scitotenv.2004.04.062.

Badireddy, A.R., Chellam, S., Yanina, S., Gassman, P., Rosso, K.M., 2008. Bismuth dimercaptopropanol (BisBAL) inhibits the expression of extracellular polysaccharides and proteins by Brevundimonas diminuta: implications for membrane microfiltration. Biotechnol. Bioeng. 99, 634-643. https://doi.org/ 10.1002/bit.21615.

Buser, H.R., Poiger, T., Muller, M.D., 1999. Occurrence and environmental behavior of the chiral pharmaceutical drug ibuprofen in surface waters and in wastewater. Environ. Sci. Technol. 33, 2529-2535. https://doi.org/10.1021/es981014w.

Chen, M.Y., Lee, D.J., Tay, J.H., Show, K.Y., 2007. Staining of extracellular polymeric substances and cells in bioaggregates. Appl. Microbiol. Biotechnol. 75, 467-474. https://doi.org/10.1007/s00253-006-0816-5.

Cy, H., Lh, F., Mh, S., Cf, H., Jp, W., Hw, K., 2020. Ibuprofen biodegradation by hospital, municipal, and distillery activated sludges. Environ. Technol. 41, 171-180. https:/ doi.org/10.1080/09593330.2018.1493146.

Falås, P., Wick, A., Castronovo, S., Habermacher, J., Ternes, T.A., Joss, A., 2016. Tracing the limits of organic micropollutant removal in biological wastewater treatment. Water Res. 95, 240-249. https://doi.org/10.1016/j.watres.2016.03.009.

Frølund, B., Griebe, T., Nielsen, P.H., 1995. Enzymatic activity in the activated-sludge floc matrix. Appl. Microbiol. Biotechnol. 43, 755-761. https://doi.org/10.1007/ BF00164784.

Frølund, B., Palmgren, R., Keiding, K., Nielsen, P.H., 1996. Extraction of extracellular polymers from activated sludge using a cation exchange resin. Water Res. 30, 1749-1758. https://doi.org/10.1016/0043-1354(95)00323-1.

Higgins, M.J., Novak, J.T., 1997. Characterization of exocellular protein and its role in bioflocculation. J. Environ. Eng. 123, 479-485. https://doi.org/10.1061/(ASCE) 0733-9372(1997)123:5(479).

Hou, X., Liu, S., Zhang, Z., 2015. Role of extracellular polymeric substance in determining the high aggregation ability of anammox sludge. Water Res. 75, 51-62. https://doi.org/10.1016/j.watres.2015.02.031.

Jenkins, D., Richard, M.G., Daigger, G., 2003. Manual on the Causes and Control of Activated Sludge Bulking, Foaming and Other Solids Separation Problems. Lewis Publishing, Boca Raton, FL.

Jia, Y., Yin, L., Khanal, S.K., Zhang, H., Oberoi, A.S., Lu, H., 2020. Biotransformation of ibuprofen in biological sludge systems: investigation of performance and mechanisms. Water Res. 170, 115303. https://doi.org/10.1016/j. watres.2019.115303.

Jin, B., Wilén, B.M., Lant, P., 2003. A comprehensive insight into floc characteristics and their impact on compressibility and settleability of activated sludge. Chem. Eng. J. 95, 221-234. https://doi.org/10.1016/S1385-8947(03)00108-6.

Joss, A., Zabczynski, S., Göbel, A., Hoffmann, B., Löffler, D., McArdell, C.S., Ternes, T.A., Thomsen, A., Siegrist, H., 2006. Biological degradation of pharmaceuticals in municipal wastewater treatment: proposing a classification scheme. Water Res. 40, 1686-1696. https://doi.org/10.1016/j.watres.2006.02.014.

Kong, Q., He, X., Feng, Y., Miao, M. Sheng, Wang, Q., Du, Y. da, Xu, F., 2017. Pollutant removal and microorganism evolution of activated sludge under ofloxacin selection pressure. Bioresour. Technol. 241, 849-856. https://doi.org/10.1016/j. biortech.2017.06.019.

Kosonen, J., Kronberg, L., 2009. The occurrence of antihistamines in sewage waters and in recipient rivers. Environ. Sci. Pollut. Res. 16, 555-564. https://doi.org/10.1007/ s11356-009-0144-2.

Langenhoff, A., Inderfurth, N., Veuskens, T., Schraa, G., Blokland, M., KujawaRoeleveld, K., Rijnaarts, H., 2013. Microbial removal of the pharmaceutical compounds ibuprofen and diclofenac from wastewater. BioMed Res. Int. 2013 https://doi.org/10.1155/2013/325806.

Lee, H.B., Peart, T.E., Svoboda, M.L., 2005. Determination of endocrine-disrupting phenols, acidic pharmaceuticals, and personal-care products in sewage by solidphase extraction and gas chromatography-mass spectrometry. J. Chromatogr. A 1094, 122-129. https://doi.org/10.1016/j.chroma.2005.07.070.

Li, X.Y., Yang, S.F., 2007. Influence of loosely bound extracellular polymeric substances (EPS) on the flocculation, sedimentation and dewaterability of activated sludge. Water Res. 41, 1022-1030. https://doi.org/10.1016/j.watres.2006.06.037.

Liao, B.Q., Lin, H.J., Langevin, S.P., Gao, W.J., Leppard, G.G., 2011. Effects of temperature and dissolved oxygen on sludge properties and their role in bioflocculation and settling. Water Res. 45, 509-520. https://doi.org/10.1016/j. watres.2010.09.010.

Liu, Y., Fang, H.H.P., 2003. Influences of extracellular polymeric substances (EPS) on flocculation, settling, and dewatering of activated sludge. Crit. Rev. Environ. Sci. Technol. 33, 237-273. https://doi.org/10.1080/10643380390814479.

Loos, R., Wollgast, J., Huber, T., Hanke, G., 2007. Polar herbicides, pharmaceutical products, perfluorooctanesulfonate (PFOS), perfluorooctanoate (PFOA), and nonylphenol and its carboxylates and ethoxylates in surface and tap waters around Lake Maggiore in Northern Italy. Anal. Bioanal. Chem. 387, 1469-1478. https://doi. org/10.1007/s00216-006-1036-7.

Loraine, G.A., Pettigrove, M.E., 2006. Seasonal variations in concentrations of pharmaceuticals and personal care products in drinking water and reclaimed wastewater in Southern California. Environ. Sci. Technol. 40, 687-695. https://doi. org/10.1021/es051380x.

Martinez, F., Favela-Torres, E., Gomez, J., 2000. Oscillations of exopolymeric composition and sludge volume index in nitrifying flocs. Appl. Biochem. Biotechnol. Part A Enzyme Eng. Biotechnol. 87, 177-188. https://doi.org/10.1385/ABAB:87:3: 177.

McSwain, B.S., Irvine, R.L., Hausner, M., Wilderer, P.A., 2005. Composition and distribution of extracellular polymeric substances in aerobic flocs and granular sludge. Appl. Environ. Microbiol. 71, 1051-1057. https://doi.org/10.1128/ AEM.71.2.1051-1057.2005.

Men, Y., Achermann, S., Helbling, D.E., Johnson, D.R., Fenner, K., 2017. Relative contribution of ammonia oxidizing bacteria and other members of nitrifying activated sludge communities to micropollutant biotransformation. Water Res. 109, 217-226. https://doi.org/10.1016/j.watres.2016.11.048.

Mesquita, D.P., Amaral, A.L., Ferreira, E.C., 2011. Identifying different types of bulking in an activated sludge system through quantitative image analysis. Chemosphere 85, 643-652. https://doi.org/10.1016/j.chemosphere.2011.07.012.

More, T.T., Yadav, J.S.S., Yan, S., Tyagi, R.D., Surampalli, R.Y., 2014. Extracellular polymeric substances of bacteria and their potential environmental applications. J. Environ. Manag. 144, 1-25. https://doi.org/10.1016/j.jenvman.2014.05.010.

Oliveira, A.S., Amorim, C.L., Ramos, M.A., Mesquita, D.P., Inocêncio, P., Ferreira, E.C., Van Loosdrecht, M., Castro, P.M.L., 2020. Variability in the composition of extracellular polymeric substances from a full-scale aerobic granular sludge reactor treating urban wastewater. J. Environ. Chem. Eng. 8, 104156. https://doi.org/ 10.1016/j.jece.2020.104156.

Ortiz de García, S.A., Pinto Pinto, G., García-Encina, P.A., Irusta-Mata, R., 2014. Ecotoxicity and environmental risk assessment of pharmaceuticals and personal care products in aquatic environments and wastewater treatment plants. Ecotoxicology 23, 1517-1533. https://doi.org/10.1007/s10646-014-1293-8.

Pasquini, L., Merlin, C., Hassenboehler, L., Munoz, J., Pons, M., Görner, T., 2013. Impact of certain household micropollutants on bacterial behavior. Toxicity tests/study of extracellular polymeric substances in sludge. Sci. Total Environ. 463-464, 355-365. https://doi.org/10.1016/j.scitotenv.2013.06.018.

Peng, J., Wang, X., Yin, F., Xu, G., 2019. Characterizing the removal routes of seven pharmaceuticals in the activated sludge process. Sci. Total Environ. 650, 2437-2445. https://doi.org/10.1016/j.scitotenv.2018.10.004.

Quintana, J.B., Weiss, S., Reemtsma, T., 2005. Pathways and metabolites of microbial degradation of selected acidic pharmaceutical and their occurrence in municipal wastewater treated by a membrane bioreactor. Water Res. 39, 2654-2664. https:// doi.org/10.1016/j.watres.2005.04.068.

Quintelas, C., Mesquita, D.P., Torres, A.M., Costa, I., Ferreira, E.C., 2020. Degradation of widespread pharmaceuticals by activated sludge: kinetic study, toxicity assessment, and comparison with adsorption processes. J. Water Process Eng. 33 https://doi.org/ 10.1016/j.jwpe.2019.101061. 
Rodriguez-Narvaez, O.M., Peralta-hernandez, J.M., Goonetilleke, A., Bandala, E.R., 2017. Treatment technologies for emerging contaminants in water : a review. Chem. Eng. J. 323, 361-380. https://doi.org/10.1016/j.cej.2017.04.106.

Roh, H., Subramanya, N., Zhao, F., Yu, C.P., Sandt, J., Chu, K.H., 2009. Biodegradation potential of wastewater micropollutants by ammonia-oxidizing bacteria. Chemosphere 77, 1084-1089. https://doi.org/10.1016/j. chemosphere.2009.08.049.

Sacher, F., Lange, F.T., Brauch, H.-J., Blankenhorn, I., 2001. Pharmaceuticals in groundwaters: analytical methods and results of a monitoring program in BadenWurttemberg, Germany. J. Chromatogr. A 938, 199-210. https://doi.org/10.1016/ S0021-9673(01)01266-3.

Sanganyado, E., Lu, Z., Fu, Q., Schlenk, D., Gan, J., 2017. Chiral pharmaceuticals: a review on their environmental occurrence and fate processes. Water Res. 124, 527-542. https://doi.org/10.1016/j.watres.2017.08.003.

Santos, J.L., Aparicio, I., Alonso, E., 2007. Occurrence and risk assessment of pharmaceutically active compounds in wastewater treatment plants . A case study : seville city (Spain). Environ. Int. 33, 596-601. https://doi.org/10.1016/j. envint.2006.09.014.

Santos, L.H.M.L.M., Araújo, A.N., Fachini, A., Pena, A., Delerue-Matos, C., Montenegro, M.C.B.S.M., 2010. Ecotoxicological aspects related to the presence of pharmaceuticals in the aquatic environment. J. Hazard Mater. 175, 45-95. https:// doi.org/10.1016/j.jhazmat.2009.10.100.

Santos, L.H.M.L.M., Gros, M., Rodriguez-Mozaz, S., Delerue-Matos, C., Pena, A., Barceló, D., Montenegro, M.C.B.S.M., 2013. Contribution of hospital effluents to the load of pharmaceuticals in urban wastewaters: identification of ecologically relevant pharmaceuticals. Sci. Total Environ. 461-462, 302-316. https://doi.org/10.1016/j. scitotenv.2013.04.077.

Sheng, G.P., Yu, H.Q., Li, X.Y., 2010. Extracellular polymeric substances (EPS) of microbial aggregates in biological wastewater treatment systems: a review. Biotechnol. Adv. 28, 882-894. https://doi.org/10.1016/j.biotechadv.2010.08.001.

Smolders, G.J.F., van der Meij, J., van Loosdrecht, M.C.M., Heijnen, J.J., 1994. Model of the anaerobic metabolism of the biological phosphorus removal process: stoichiometry and $\mathrm{pH}$ influence. Biotechnol. Bioeng. 43, 461-470. https://doi.org/ 10.1002/bit.260430605.
Song, C., Sun, X.F., Xing, S.F., Xia, P.F., Shi, Y.J., Wang, S.G., 2014. Characterization of the interactions between tetracycline antibiotics and microbial extracellular polymeric substances with spectroscopic approaches. Environ. Sci. Pollut. Res. 21, 1786-1795. https://doi.org/10.1007/s11356-013-2070-6.

Ternes, T.A., 1998. Occurrence of drugs in German sewage treatment plants and rivers. Water Res. 32, 3245-3260. https://doi.org/10.1016/S0043-1354(98)00099-2.

Tian, X., Shen, Z., Han, Z., Zhou, Y., 2019. The effect of extracellular polymeric substances on exogenous highly toxic compounds in biological wastewater treatment : an overview. Bioresour. Technol. Reports 5, 28-42. https://doi.org/ 10.1016/j.biteb.2018.11.009.

Verenitch, S.S., Lowe, C.J., Mazumder, A., 2006. Determination of acidic drugs and caffeine in municipal wastewaters and receiving waters by gas chromatography-ion trap tandem mass spectrometry. J. Chromatogr. A 1116, 193-203. https://doi.org/ 10.1016/j.chroma.2006.03.005.

Wilén, B.M., Jin, B., Lant, P., 2003. The influence of key chemical constituents in activated sludge on surface and flocculating properties. Water Res. 37, 2127-2139. https://doi.org/10.1016/S0043-1354(02)00629-2.

Wilén, B.M., Lumley, D., Mattsson, A., Mino, T., 2008. Relationship between floc composition and flocculation and settling properties studied at a full scale activated sludge plant. Water Res. 42, 4404-4418. https://doi.org/10.1016/j. watres.2008.07.033.

Zhang, H., Song, S., Jia, Y., Wu, D., Lu, H., 2019. Stress-responses of activated sludge and anaerobic sulfate-reducing bacteria sludge under long-term ciprofloxacin exposure. Water Res. 164 https://doi.org/10.1016/j.watres.2019.114964.

Zhou, G., Li, N., Rene, E.R., Liu, Q., Dai, M., Kong, Q., 2019. Chemical composition of extracellular polymeric substances and evolution of microbial community in activated sludge exposed to ibuprofen. J. Environ. Manag. 246, 267-274. https:// doi.org/10.1016/j.jenvman.2019.05.044.

Zupanc, M., Kosjek, T., Petkovšek, M., Dular, M., Kompare, B., Širok, B., Blažeka, Ž., Heath, E., 2013. Removal of pharmaceuticals from wastewater by biological processes, hydrodynamic cavitation and UV treatment. Ultrason. Sonochem. 20 , 1104-1112. https://doi.org/10.1016/j.ultsonch.2012.12.003. 